\title{
Proceeding
}

Supplementary Issue: Autumn Conferences of Sports Science. Costa Blanca Sports Science Events, 2-3 November 2018.

Alicante, Spain

\section{Correlation between vestibular and spatial system in vertical dance performance}

\author{
MASSIMO ROSSATO ${ }^{1,2}$, ALESSANDRA NART $^{3} \Delta$, VINCENZO BIANCALANA ${ }^{1}$, STEFANO SCARPA $^{4}$ \\ ${ }^{1}$ Department of Biomolecular Sciences, University of Urbino, Italy \\ ${ }^{2}$ Postural Equip Academy, Venezia, Italy \\ ${ }^{3}$ Department of Biomedical, University of Study, Padua, Italy \\ 4University "Giustino Fortunato" of Benevento, Italy
}

\begin{abstract}
The aim of this study is to evaluate how the vestibular response intervenes in the adaptation of the body in a different support plan than the usual one (walls). Method The experimental group (EG) was 10 subjects $(M=30,8 ; S D= \pm 10.00)$. For each test time, $T 0$ (before training) and T1 (after training), the experimental group underwent with 3 stabilometric evaluations considering only the best. The Cyber Sabots ${ }^{\mathrm{TM}}$ stabilometry was used in open/closed eyes (OE/CE) for evaluation the effects of a vertical dance training. Descriptive analysis compares the postural profile variables between experimental and control group (CG) (Rossato et al, 2013). The T-Student analysis was significance in: $\mathrm{Wz}(.5-2 \mathrm{~Hz})(\mathrm{CE})(\mathrm{p}=.05)$ and $\mathrm{Wz}(2-\mathrm{MaxHz})(\mathrm{OE})(\mathrm{p}=.006)$. Oneway ANOVA underlined statistical significance in: Ym (OE-CE/T0-T1) ( $p=.02)$, SURFACE (OE-CE/T0-T1) $(p=.06)$, VARVIT (OE-CE/T0-T1) $(p=.05), W z(0-.5 \mathrm{~Hz})(\mathrm{OE}-\mathrm{CE} / \mathrm{TO}-\mathrm{T} 1)(p=.002), \mathrm{Wz}(2-\mathrm{MaxHz})$ (OE-CE/T0T1) $(p=.00)$, AVD (OE-CE/T0-T1) ( $p=.007)$, TalD (OE-CE/TO-T1) $(p=.007)$. Variables considered were confirmed by post-hoc Bonferroni test. The EG shows a statistical significance on the Wz frequencies $(0,5-$ $2 \mathrm{~Hz} ; 2-\mathrm{MaxHz}$ ) related to vestibular system in the Fourier Transform (FFT). The significance in open eyes postural profile variables may strengthen the interdependence of visual and vestibular system. Key words: Vestibular and spatial system; Vertical dance performance; Stabilometric assessment.
\end{abstract}

\section{Cite this article as:}

Rossato, M., Nart, A., Biancalana, V., \& Scarpa, S. (2019). Correlation between vestibular and spatial system in vertical dance performance. Journal of Human Sport and Exercise, 14(1proc), S115-S125. doi:https://doi.org/10.14198/ihse.2019.14.Proc1.14

Corresponding author. Department of Biomedical, University of Study, Padua, Italy.

E-mail: alessandra.nart@unipd.it

Supplementary Issue: Autumn Conferences of Sports Science. Costa Blanca Sports Science Events, 2-3 November 2018. Alicante, Spain.

JOURNAL OF HUMAN SPORT \& EXERCISE ISSN 1988-5202

(c) Faculty of Education. University of Alicante.

doi:10.14198/jhse.2019.14.Proc1.14 


\section{INTRODUCTION}

Vertical dance is a form of body expression that uses techniques derived from contemporary dance combined with work at height; it is a spatial practice in which the dancer's body is engaged in defining borders and boundaries in vertical and aerial territories interacting with a variety of sensibilities, knowledge and skills. For this purpose, part of the climbing equipment kit, such as ropes and harnesses, is used to keep the dancers suspended, as well as other devices, such as descenders, karabiners and sundry other aids intended to ensure safety during practice, which are loan devices taken, among other things, from the equipment kit used in work at height (such as construction work, tree growing, securing of rocky walls).

The performer is secured by means of a rope, which is in turn placed in the highest part of the buildings or other vertical structures upon which s/he moves. It involves positioning the body perpendicular to the wall, and the vertical surface is used as a dancing floor; the person moves sweeping through the air as well, thus turning perspectives upside down and expanding the possibilities of movement. The training method exploits the body gravity and weight to perform proprioception, stretching, and strengthening exercises, as well as others designed to promote movement of the joints, perception, balance and support, progressions that are useful for the preparation to body movement to be performed in a position perpendicular to the vertical plane (Wilson et al, 2015).

We can therefore easily understand how, in the aerial phase, dancers are required to achieve continuous adaptation in search of balance and postural control. The body spatial references are distorted, and the adaptations required constantly stimulate the dancer to put in place sensorimotor changes and, in particular, the optical-vestibular analysers to integrate with the proprioceptors coming from the main postural muscles, including - among others - the trapezium, the sternocleidomastoid muscle and the soleus, as well as their respective antagonists (Purves et al, 2009).

In man, the reference posture is the orthostatic position on bipodalic support (Paillard 1971; Paillard, 1974), which can however take on different attitudes depending on the person, with respect to the task and the environment in which the latter lives (Shumway-Cook \& Woollacott, 2007).

Under normal conditions, the regulation of an upright posture involves not only the sensory information of the visual, vestibular and proprioceptive receptors, but also the somatosensory information of the cutaneous mechanoreceptors located on the sole of the feet (Roll JP \& Roll R, 1987). This set of information as a whole contributes, all together, to the reflex regulation of balance, with further proprioceptive input on the central nervous system. An efficient central somatosensory process plays a key role for the development of an effective strategy aimed at maintaining a postural balance and a kinaesthetic balance for stabilising the body while maintaining a high-level sport activity.

Actually, the first information that an athlete receives, together with visual one, is the proprioceptive information sent by his own foot receptors (Sévérac et al, 1996; Hufschmidt et al, 1980; Thompson et al, 2003). Under conditions of flight equilibrium in which the podalic system is lacking, between the information coming from sight and those coming from our proprioception system, the vestibular system plays a more important role in the regulation and maintenance of posture (Lévêque et al, 2009). Vertical dance is one of the disciplines that involve a very high vestibular load. In sports involving elements of flight and rotary and acrobatic movements such as diving, athletes are subjected to a very high vestibular load, as there is a strong relationship between stressed vestibular stimuli and the displacement of the visual reference that stimulate the semi-circular canals (Surkov, 1986). The vestibular system is therefore considered not only 
as a true sensory system, due to the fact that it is integrated with visual and somatosensory information, but also as a motor system, as it controls the movement of the eyes, trunk and head via the vestibulospinal pathway (Herdman \& Richard, 2014).

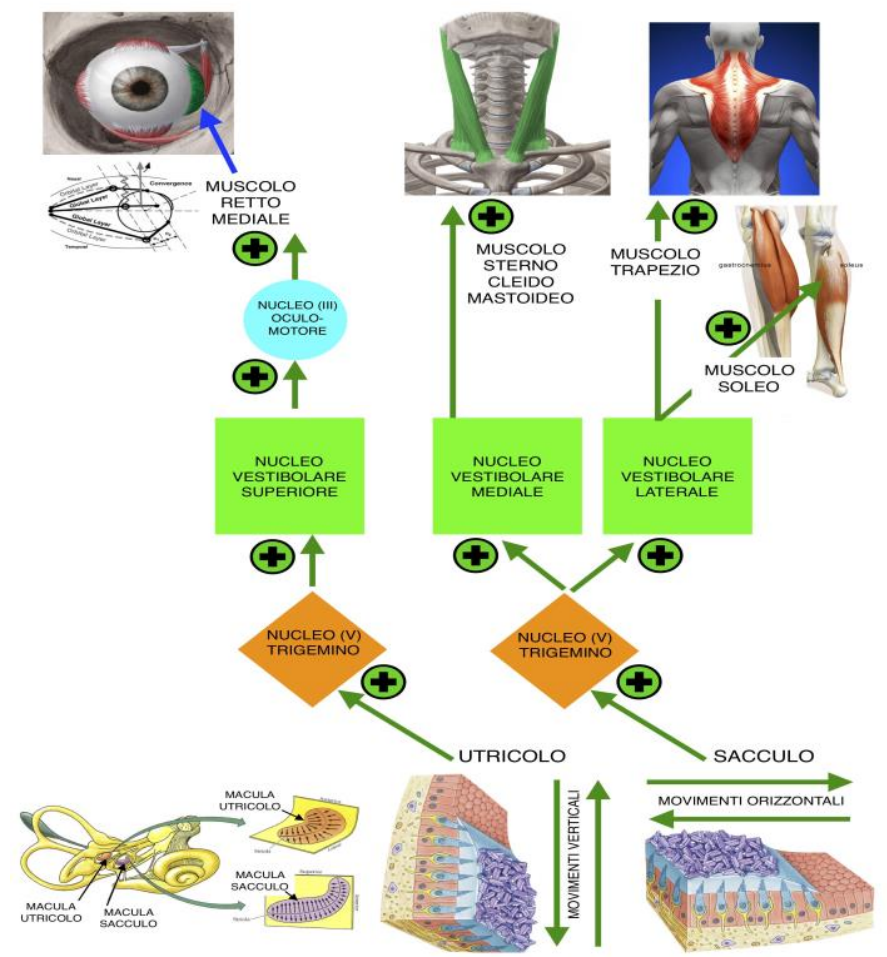

Figure 1. The vestibular pathways (Rossato,@-2017)

\section{Hypotheses}

The aim of this study was to evaluate how the vestibular response intervenes in the adaptation of the body in a different support plan than the usual one (walls) through the electronic stabilometric platform in static mode with open eyes (OE) and closed eyes (CE) before and after training. To make our research objective and compare the experimental sample obtained with the sample considered in the guidelines of Dr. Rossato (2013), the stabilometric examination was performed using a Cyber Sabots ${ }^{\mathrm{TM}}$ platform in static mode with open eyes and closed eyes.

\section{MATERIALS AND METHODS}

\section{Participants}

The experimental group (EG) was $10 \mathrm{~F}$ subjects $(M=30,8 ; S D= \pm 10.00)$ attending vertical dance courses at the sports centre-C. Reyer-Venice. The subjects were informed of the project and voluntarily joined by signing the informed consent. In the case of minors, the consent was signed by their parents.

The subjects were selected according to specific inclusion criteria (i.e. medical certificate of sports fitness, participants in the experimental vertical dance course, absence of traumatic foot injuries, Near Point of Convergence (NPC) test, absence of nystagmus, absence of alterations of the vestibular or equilibrium system, absence of inflammatory and degenerative diseases of the central nervous system). 


\section{Measures}

Each participant underwent a set of tests, namely:

- Ocular convergence test (NPC) aimed at observing the behaviour of maximum muscle activity of the eyes (Barraut, 1997) as well as leaving out the presence of nystagmus, a more specific sign of vestibular pathologies (Guidetti, 2002);

-The Cyber Sabots ${ }^{\mathrm{TM}}$ stabilometry was used in open/closed eyes (OE/CE) for evaluation the effects of a vertical dance training; the data were processed using the SabotSoftwareVib software.

\section{Stabilometry}

Posture and balance control requires a complex interaction of sensory, motor inputs and processes of the Central Nervous System (CNS) that our brain must coordinate.

A person standing in an upright position is compared to a reverse pendulum (tibiotarsic articulation pivot), the rest of the body being in continuous oscillation in order to maintain the PC within the support polygon (Ouaknine, 2005). From a scientific point of view, Postural Control (hereinafter PC) is the resultant of all force vectors, i.e. the sum vector (Gagey et al, 1990; Peterka, 2002). Thus, the stabilometric platform measures the average PC position of the body and of its small movements around said position. The force vectors that are applied to the support surface are converted into electrical signals and processed by software that, by means of appropriate analyses, obtains their specific values (Rossato et al, 2013).

\section{Procedures}

The selected dancers were subjected to a stabilometric assessment during the acute phase in 2 distinct stages, namely: before vertical dance training (TO) and after training (T1) in static mode (OE/CO). The stabilometric test was performed at a sampling rate of $40 \mathrm{~Hz}$, with a duration of 51.2 seconds with open eyes (OE) and with closed eyes (CE), respectively, with bare feet positioned at $30^{\circ}$ (APF85/AFP99). The stabilometric platform was placed at a distance of $240 \mathrm{~cm}$ from the optical target (i.e. the vertical line on the wall) to objectify the verticality (Kapoula \& Lê, 2006; Matheron et al, 2006). For each test time, T0 (before training) and T1 (after training), the experimental group underwent 3 stabilometric evaluations considering only the best.

Following the first acquisition, we continued with a session vertical dance training in suspension, in which the body was hanging through the harness from a long rope that lowered from the ceiling. The training session continued for 50 minutes requiring the execution of pendulum movements aimed at learning how to control the body while vaulting in the air, runs followed by leaps in the void, inversions, and run-ups.

\section{Analysis}

The results collected through the stabilometric platform software were then stored in an Excel database including, for each subject, the variables/frequencies (Wz) most suitable for our study. The Wz are highlighted in the Fast Fourier Transform (FFT).

The stabilometric signal can be divided into three frequency bands, namely: 1) from 0 to $0.5 \mathrm{~Hz}$ - natural frequency of the human body, i.e. the real oscillations of the pressure centre. The system detects visual, proprioceptive inputs, movements related to breathing; 2) from $0.5 \mathrm{~Hz}$ to $2 \mathrm{~Hz}$ - values expressing conscious and unconscious proprioception disorders (starting from $1 \mathrm{~Hz}$ ); 3 ) components greater than 2 to $20 \mathrm{~Hz}$, including oscillations at the start from the central nervous system (CNS) (Rossato et al, 2003). 


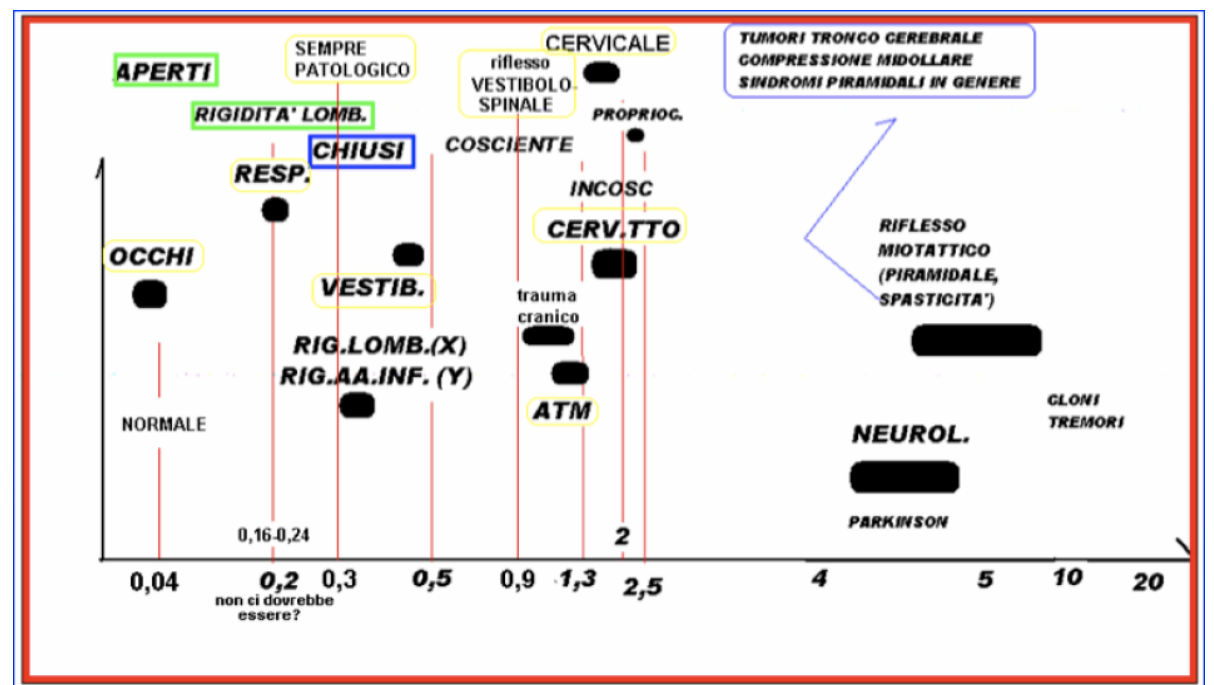

Figure 2. Diagram of frequencies proposed by Montoya. (Rossato et al,2013)

For statistical analysis, the Statistica 7.0 StatSoft Inc programme was used. Descriptive analysis compares the postural profile variables between experimental (EG) and control group (CG) (Rossato et al, 2013) to check the normality of data distribution. Thereafter, we proceeded with the parametric tests, namely: T-test and One-Way Anova in order to ascertain whether within the parameters considered any change occurred between the different modes (OE/CE-T0/T1). The test was performed with a 95\% confidence interval, and for significance the $p$-value $\leq 0.05$ was considered. The post-hoc Bonferroni test was performed in the event that any statistical significance should be found. The analysis of the data so collected allowed making a comparison within the group itself and between the latter compared to the reference sample considered in the study of Dr. Rossato (2013) to investigate the effect of Vertical Dance training on the dancer's performance.

\section{RESULTS}

The T-Student analysis was significant in Wz (.5-2Hz) (CE) ( $p=.05)$ (Diagram 1) and Wz (2-MaxHz) (OE) $(p=.006)$ (Diagram 2). One-way ANOVA showed statistical significance in: Ym (Diagram 3) (OE-CE/T0-T1) $(p=.02)$, SURFACE (Diagram 4) (OE-CE/T0-T1) ( $p=.06)$, VARVIT (Diagram 5) (OE-CE/T0-T1) $(p=.05)$, Wz $(0-.5 \mathrm{~Hz})$ (Diagram 6) (OE-CE/T0-T1) ( $p=.002)$, Wz (2-MaxHz) (Diagram 7) (OE-CE/T0-T1) ( $p=.00)$, AVD (Diagram 8) (OE-CE/TO-T1) $(p=.007)$, TalD (Diagram 9) (OE-CE/TO-T1) $(p=.007)$.

\section{T-Student}

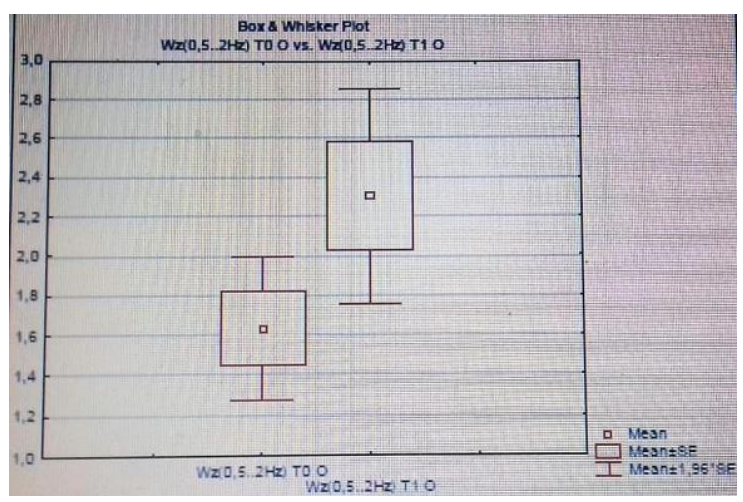

Diagram 1. EG: Wz $(0,5 . .2 \mathrm{~Hz})(\mathrm{OE}) \mathrm{T} 0-\mathrm{T} 1 \mathrm{p}=.05$ 


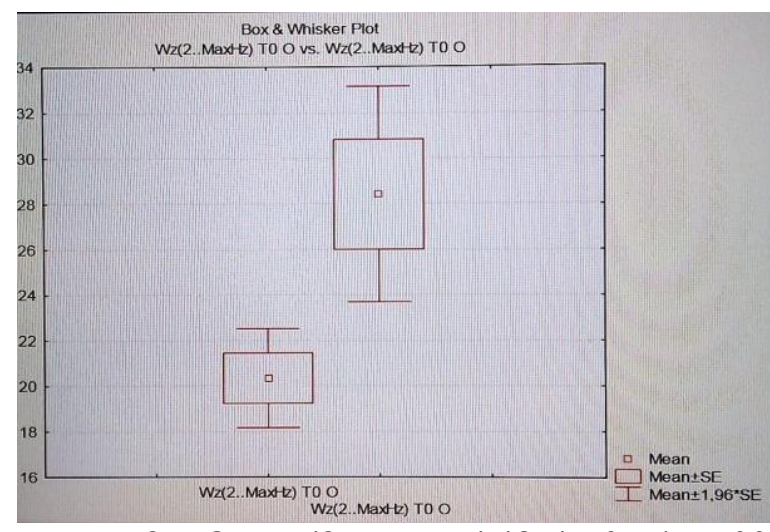

Diagram 2. EG: Wz (2...MaxHz) (OE) T0-T1 p=.006

\section{ANOVA}

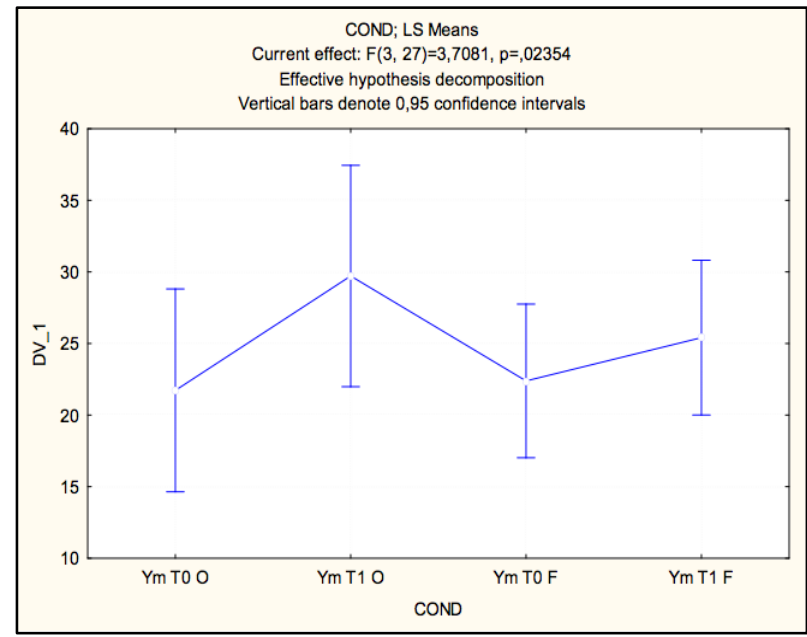

Diagram 3. EG: Ym (OE-CE) T0-T1 p=.02

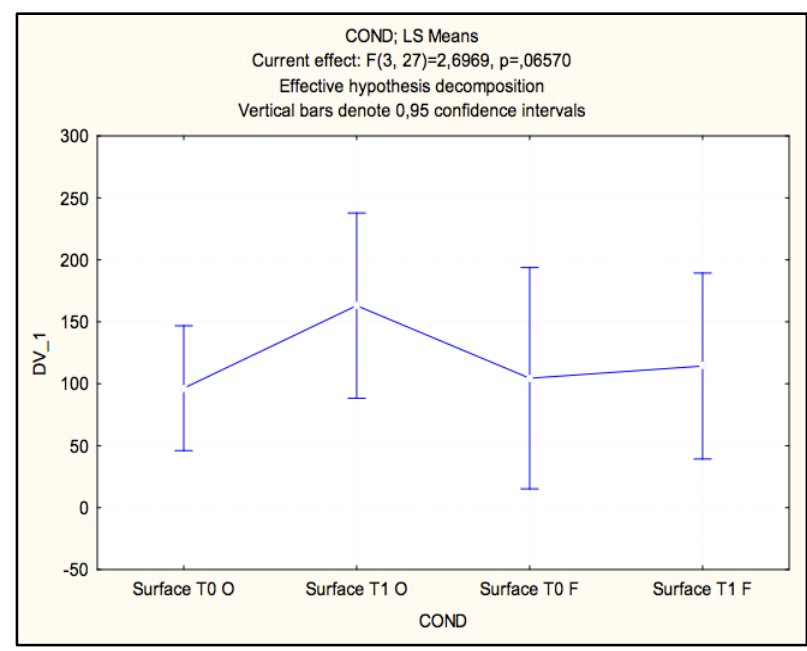

Diagram 4. EG: SURFACE(OE-CE)T0-T1 $p=.06$ 


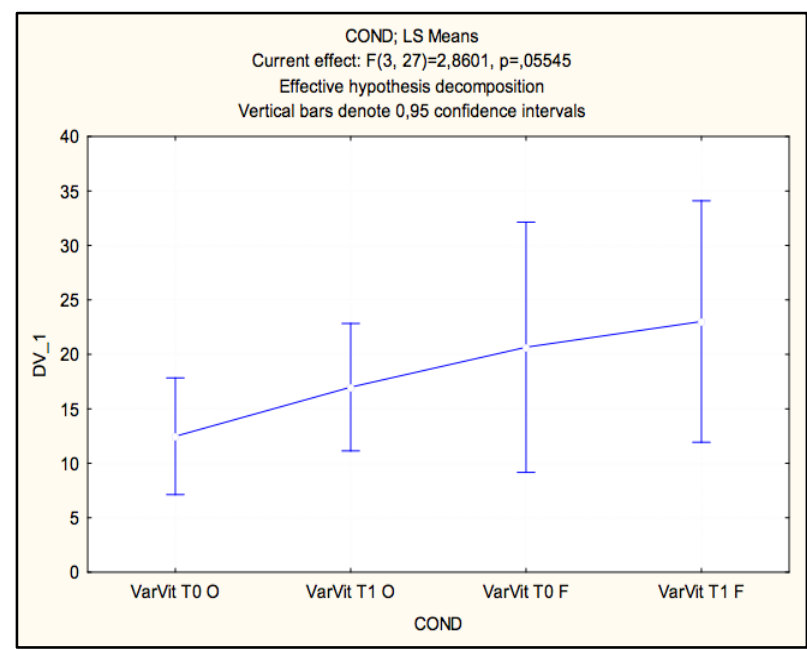

Diagram 5. EG: VARVIT (OE-CE) T0-T1 p=.05

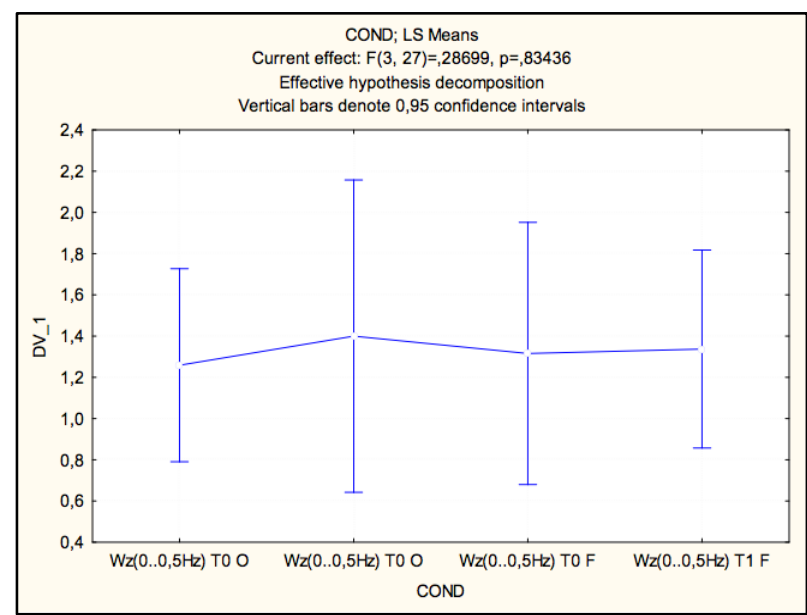

Diagram 6. EG: Wz (0..0,5Hz) (OA-OC) T0-T1 p=.002

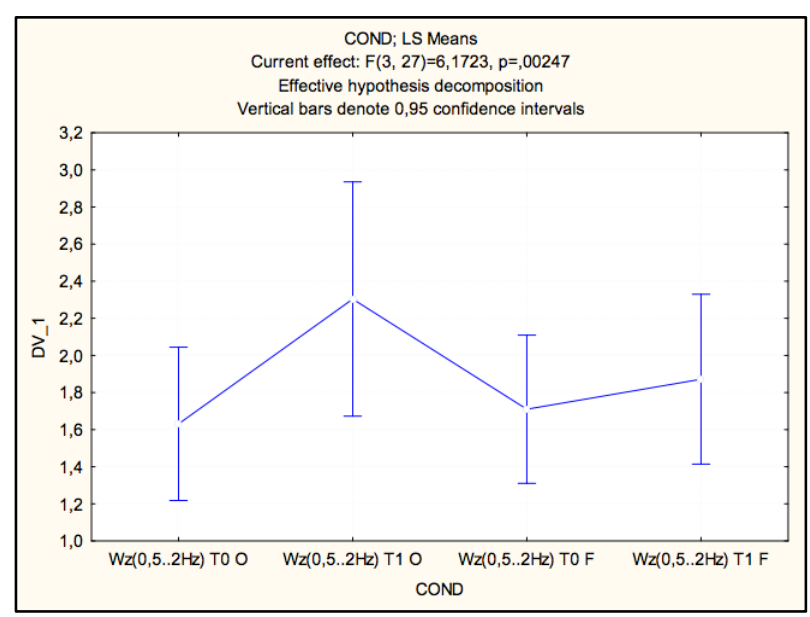

Diagram 7. EG: Wz (2...MaxHz) (OE-CE) T0-T1 p=.00 


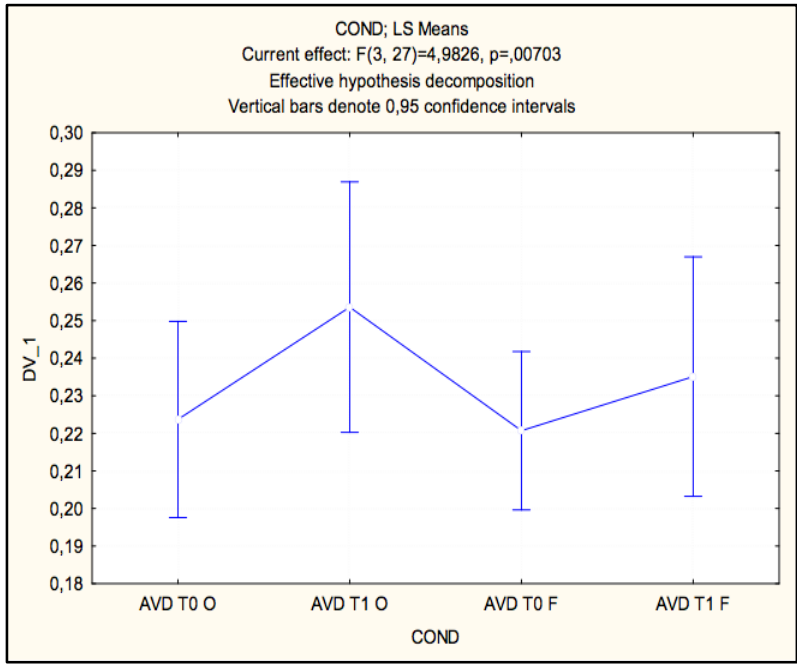

Diagram 8. EG: AVD (OE-CE) T0-T1 $p=.007$

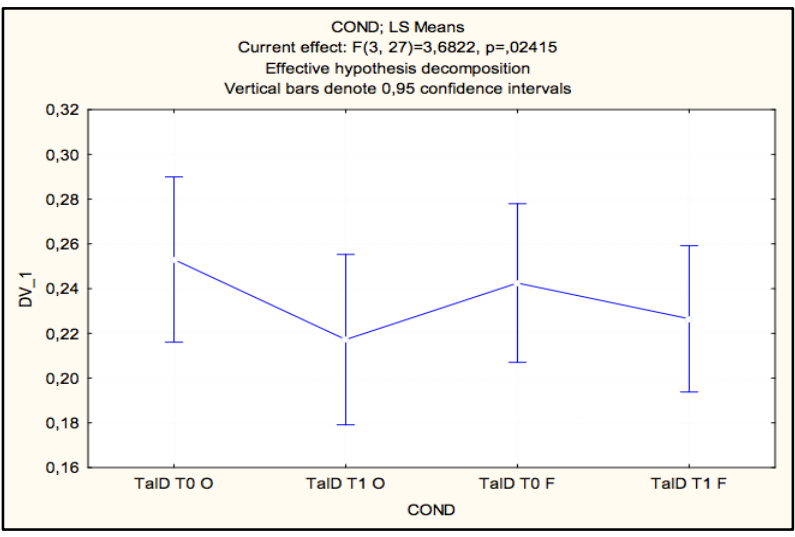

Diagram 9. EG: TaID (OE-CE) T0-T1 $p=.007$

The variables considered were confirmed by post-hoc Bonferroni test.

\section{DISCUSSION}

The EG shows a statistical significance on the Wz frequencies $(0.5-2 \mathrm{~Hz} ; 2-\mathrm{MaxHz})$ related to vestibular system in the Fourier Transform (FFT). The significance in open eyes postural profile variables may strengthen the interdependence of visual and vestibular system.

Actually, the EG athletes in the stabilometry evaluation at $\mathrm{T} 0$ already showed a stable general postural profile with respect to $\mathrm{GC}$, highlighting the occurrence of unusual alterations on the higher frequencies between 2 and $20 \mathrm{~Hz}$. Frequencies were also found at T1 higher than the average of the GC as well as compared with the average of the GS at T0. These peaks are present in the postural profiles of subjects with vestibular disorders; none of the girls (exclusion criterion) showed neurological-vestibular problems (Ickenstein et al, 2012; Nacci et al, 2017).

We can do nothing but assume that this is a physiological response related to an adaptation of the vestibular system following the specific vertical dance training session. Indeed, during training, the body is subjected to a very high vestibular load and therefore needs to respond to very demanding and stimulating requests 
with regard to the vestibular apparatus. The medium-low frequencies $(0-0.5 \mathrm{~Hz}$ and $0.5-2 \mathrm{~Hz})$ lower than the average already at T0 suggest that the bands linked to the management of postural and sensorimotor control are by now stable and accustomed to such type of training, so that the body will respond by soliciting the area concerning the CNS on an involuntary level, showing peaks on the side of the higher frequencies.

This most likely derives from the fact that they already undergo specific training (6/8 months) on the vestibular side, which might have generated automatisms (Simonsen, 2014; Khan et al, 2016).

The frequencies from $2 \mathrm{~Hz}$ onwards describe subcortical activity at the level of the cerebellum in which the unconscious - and therefore involuntary part is stimulated (Lévêque et al, 2009).

Furthermore, the analysis of the data highlighted a statistically significant correlation of the differences linked more to the $\mathrm{T} 1$ - open eyes - test than to the T0 test: the presence of the visual element (OE) accounted for a significant value, showing that the integration of work on the vertical plane passes mainly through the eye, creating an addiction of the latter (Berthoz et al, 1975).

\section{CONCLUSION}

In conclusion, we may state that the athlete-dancers have an excellent postural balance, better than the average. The significant increase in some parameters with a frequency dimension $(0-0.5 \mathrm{~Hz} / 0.5-20 \mathrm{~Hz})$ suggests that an adaptation is put in place by the vestibular system (study started after $6 / 8$ months of training), recalling a possible response by the subcortical system as well.

\section{REFERENCES}

Alima, S.A., Rowen, K.A., \& lles, J.F. (2003). Vestibular actions on back and lower limb muscles during postural tasks in man. J.Physiol, Jan15;546(Pt2):615-624.

Barraud-Crouzet, D. (1997). Des perturbations posturales qui étonnent l'orthoptiste, "Posture et environment" Eds M. Lacour, P. M. Gagey \& B. Weber, Sauramps médical Montpellier, pp. 161-162.

Berthoz, A., Pavard, B., \& Young, L. R. (1975). Perception of linear horizontal self-motion induced by peripheral vision (linearvection) basic characteristics and visual-vestibular interactions. Exp Brain Res; 23:471-489. https://doi.org/10.1007/BF00234916

Brandt, T., \& Dieterich, M. (2004). Postural imbalance in peripheral and central vestibular disorders. In: Bronstein, A.M., Brandt, T., Woollacott MH, Nutt JG. Clinical Disorders of Balance, Posture and Gait. 2nd ed. London: Arnold, 2004;146-162.

Dieterich, M., \& Brandt, T. (2010). Imaging cortical activity after vestibular lesions. Restor Neurol Neurosci;28:47-56.

Farfel, V. S., (1988). Il controllo dei movimenti sportivi, Società Stampa Sportiva, Roma.

Francesconi, K., \& Gandini, G. (2015). L'intelligenza nel movimento. Percezione, propriocezione, controllo posturale, Edi-Ermes,Milano.

Fukuda, T. (1961). Studies in human dynamic postures from the viewpoint of postural reflexes, Acta Otolaryngol. suppl. 1-52, 161.

Gagey, P.M., Agey, P.M, Bizzo, G., Bonnier, L., Gentaz, R., Guillaume, P., \& Marucchi, C. (1990). Huit leçons de Posturologie. 5012 Paris, Association française de posturologie.

Guidetti, G., \& Marchioni, D. (2002). Vestibolo e sport. Edizioni Martina,Bologna.

Herdman, S., \& Richard, C. (2014). Vestibular Rehabilitation (Contemporary Pespectivs in Rehabilitation. F.A. David Company-Philadelphia. 
Horak, F.B. (2007). Role of the vestibular system in postural control. In: Herdman SJ. Vestibular Rehabilitation. 3rd ed. Philadelphia: F.A. Davis Co.;32.

Hufschmidt, A., Dichgans, J., Mauritz, K.H., \& Hufschmidt, M. (1980). Some methods and parameters of body quantification and their neurological applications. Arch Psychiatr Nervenk: 135-50.

Ickenstein, G.W., Ambach, H., Klöditz, A., Koch, H., Isenmann, S., Reichmann, H., \& Ziemssen, T. (2012). Static posturography in aging and Parkinson's disease, Front Aging Neuroscience. Aug 6;4:20. https://doi.org/10.3389/fnagi.2012.00020

Kapoula, Z., \& Le, T.T. (2006). Effects of distance and gaze position on postural stability in young and old subjects. Exp Brain, 173(3):438-45. https://doi.org/10.1007/s00221-006-0382-1

Kavounoudias, A., Roll, J.P., \& Roll, R. (1998). The plantar sole is a 'dynamometric map' for human balance control. Laboratoire de Neurobiologie Humaine, Université de Provence, Marseille, France. NeuroReport 9, 3247-3252. https://doi.org/10.1097/00001756-199810050-00021

Khan, A.S., Patrick, S.K., Roy, F.D., Gorassini, M.A., \& Yang, J.F. (2016). Training-Specific Neural Plasticity in Spinal Reflexes after Incomplete Spinal Cord Injury, Neural Plasticity: 671863. https://doi.org/10.1155/2016/6718763

Khon, F.P.M., \& Ritzmann, R. (2017). Gravity and neuronal adaptation, in vitro and in vivo -from neuronal cells up to neuromuscular responses: a first model, Eur Biophys J.; 47(2): 97-107. https://doi.org/10.1007/s00249-017-1233-7

Lephart, S.M., \& Fu, F.H. (1995). The role of proprioception in the treatment of sports injuries. Sports Ercise and Injury 1,96-102.

Lephart, S.M., Pincivero, D.M., Giraldo, J.L., \& Fu, F.H. (1997). The role of proprioception in the management and rehabilitation of athletic injuries. Am J Sports Med, Jan-Feb,25(1):130-7.

Léveque, Y.,Muggleton, N., Stewart, L., Schon, D. (2013). Involvement of the larynx motor area in singing-voice perception: a TMS study. Front Psychol, 4:418. https://doi.org/10.3389/fpsyg.2013.00418

Léveque M, Seidermann L, Ulmer, E., \& Chays A. (2009). Physiologie vestibulaire: bases anatomiques, cellulaire, immunohistochimiques et électrophysiologiques, Elsevier Masson SAS.

Matheron, E., Quercia, P., Weber, B., \& Gagey, P.M. (2005). Vertical heterophoria and postural deficiency syndrome. Gait Posture 21(suppl 1):S132-S2023. https://doi.org/10.1016/S09666362(05)80437-0

Meiry, J.L. (1958). The vestibular system and human dynamic space orientation, Institute of Technology. Israele.

Nacci, A., Romeo, S.O., Berrettini, S., Matteucci, J., Cavaliere, M.D., Mancini, V., Panicucci, E., Ursino, F., \& Fattori, B. (2017). Stabilometric findings in patients affected by organic dysphonia before and after phonomicrosurgery, Acta Otorhinolaryngol Ital. Aug; 37(4):286-294. https://doi.org/10.14639/0392-100X-1035

Nart, A. (2014). L'eyes-feet/ness e l'engramma posturale. Ruolo ed effetto della propriocezione attraverso valutazione stabilometrica. cfr. Dottorato di Ricerca in Metodologie Molecolari e MorfoFunzionali Applicate all'Esercizio Fisico. Università degli Studi di Urbino, Dipartimento di Scienze Biomolecolari.

Ouaknine, M. (2005). Pedana stabilometrica, Giornate Internazionali di Posturologia, Torvergata Università Roma 12-13 marzo.

Ouaknine, M., (2007). Les sabots dynamometriques: la conception du statodynamique, Conference sur invitation aux entretiens de Bichat, Paris 15 septembre.

Paillard J. (1971). Les déterminants moteurs de l'organisation de l'espace. Cahiers de Psychologie, 14 : 261-316. 
Paillard J., \& Brouchon M. (1974). A proprioceptive contribution to the spatial encoding of position cues for ballistic movements Brain Research, 71 : 273-284. https://doi.org/10.1016/0006-8993(74)909718

Peterka, R.J. (2002). Sensorimotor integration in human postural control. J. Neurophysiol. Sep,88(3): 1097-118.

Purves, D., George, J., Augustine, D., Fitzpatrick, W.C., Hall, A.-S., Lamantia J.O., MCnamara, S., \& Mark. W. (2009). Neuroscienze. Publishers Sunderland, Massachusetts U.S.A.

Roll, J.P., \& Roll, R. (1987). Kinesthesic and motor effects of extraocular muscle vibration in man, Eye movements. Amsterdam J.K O'Regan\&A, Lev-Schoen; 57-58.

Rossato, M., Bourgeois, P., \& Ouaknine, M. (2013). Stabilometry standard guidelines 2011-2013 during clinical practice, Marrapese editore, Roma.

Schone, H., (1964). On the role of gravity in human spatial orientation, Aerospace Medicine, 35, 764 772.

Schubert, M.C., \& Zee, D.S. (2010). Saccade and vestibular ocular motor adaptation (2010) RestorNeurol-Neurosci,28(1):9. https://doi.org/10.3233/RNN-2010-0523

Severac, C.A, Bousquet, P., Costes Salon, M.C., Dupui, P., \& Bessou, P. (1997). Monaural and binaural galvanic vestibular stimulation in human dynamic balance function. Gait and Posture.;6:210-217. https://doi.org/10.1016/S0966-6362(97)00011-8

Shumway-Cook, A., \& Woollacott, M., (2007). Motor Control: Translating Research Into Clinical Practice. Lippincott Williams \& Wilkins.

Thompson, P.D., Buchner, D., lleana, L.P., Gary J., \& Balady, G.J. (2003). Exercise and Physical Activity in the Prevention and Treatment of Atherosclerotic Cardiovascular Disease: A Statement From the Council on Clinical Cardiology (Subcommittee on Exercise, Rehabilitation, and Prevention) and the Council on Nutrition, Physical Activity, and Metabolism (Subcommittee on Physical Activity. Physical Activity and Pubblic Health 6-24-2003.

Leveque, Y., Muggleton, N., Stewart, L., Schon, D., (2013). Involvement of the larynx motor area in singing-voice perception: a TMS study. Front Psychol-4:418.

Simonsen, E.B. (2014). Contributions to the understanding of gait control, Danish Medical Journal, 61 (4): B4823.

Simmons, R.W. (2005). Sensory organization determinants of postural stability in trained ballet dancers. International Journal of Neuroscience. Jan;115(1):87-97.

Wilson, M., Dai, B., Zhu, A., \& Humphrey, N. (2015). Estimating trunk muscle force in vertical dance. J Dance Med Sci. 2015 Dec;19(4): 163-72. https://doi.org/10.12678/1089-313X.19.4.163

Surkov, E.N. (1986.). Psicomotricità dell'atleta. Società Stampa Sportiva, Roma.

\section{(9) $(\mathbb{Q} \Theta \Theta$}

This work is licensed under a Attribution-NonCommercial-NoDerivatives 4.0 International (CC BY-NC-ND 4.0). 